DOI:10.2478/rrlm-2019-0013

\title{
Assessment of Serum Ischemia-modified albumin, Prolidase and Thiol-Disulphide Levels in Subjects With Breast Cancer
}

\author{
Sedat Abusoglu ${ }^{1 *}$, Duygu Eryavuz ${ }^{2}$, Ceylan $\mathrm{Bal}^{3}, \mathrm{Cemil} \mathrm{Nural}^{3}$, Erel Ozcan ${ }^{3}$, \\ Mehmet Yildirimel ${ }^{1}$, Saadet Celik $^{4}$, Ali Unlu ${ }^{1}$ \\ 1. Department of Biochemistry, Selcuk University Faculty of Medicine, Turkey \\ 2. Selcuk University Faculty of Medicine,Department of Biochemistry, Turkey \\ 3. Department of Biochemistry, Yildirim Beyazlt University Faculty of Medicine, Turkey \\ 4. Department of Biochemistry, Public Health Laboratory, Bilecik, Turkey
}

\begin{abstract}
Background: Oxidative damage is of great importance for patients with breast cancer. Thus, studies were performed to identify the relationship between breast cancer and oxidative stress biomarkers.

Objectives: In this study, our aim was to find out the oxidative and antioxidant status, serum thiol-disulphide levels in subjects with breast cancer.

Methods: This study was conducted between March and June 2018 with 82 control subjects (aged between 3267 years) and 127 breast cancer patients (aged between 27-66 years) ( $p=0.058$ ) in Selcuk University Faculty of Medicine, Konya, Turkey. Serum myeloperoxidase (MPO), catalase, prolidase were analyzed with kinetic spectrophotometric and thiol-disulphide, ischemia-modified albumin (IMA), ceruloplasmin were detected by colorimetric methods.

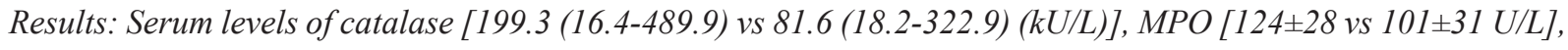
disulphide [25 (11-61) vs 18 (2-41) $\mu \mathrm{mol} / \mathrm{L}]$, IMA [0.66 (0.31-3.30) vs 0.62 (0.19-1.31) absorbance unit (ABSU)]

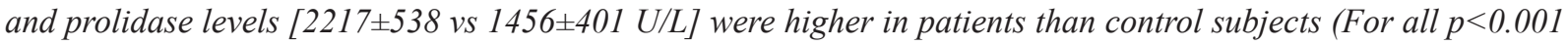

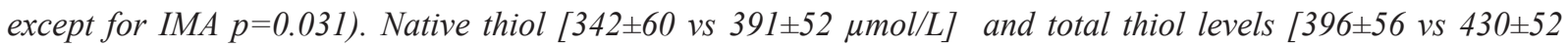
$\mu \mathrm{mol} / \mathrm{L}]$ were lower in patients compared with the control group (For all $p<0.001$ ).

Conclusions: Levels of serum thiol/disulphide and prolidase might be reliable indicators for determining oxidative status in certain patient populations.
\end{abstract}

Keywords: breast cancer, ischemia modified albumin, oxidative stress, prolidase, thiol-disulphide

Received: $1^{\text {st }}$ November 2018; Accepted: $7^{\text {th }}$ January 2019; Published: $18^{\text {th }}$ January 2019

*Corresponding author: Sedat Abusoglu, Department of Biochemistry, Selcuk University Faculty of Medicine Konya, Turkey. E-mail: sedatabusoglu@yahoo.com 


\section{Introduction}

Breast cancer is the most widely detected malignancy in females all over the world. The availability of reactive oxygen species (ROS) in an environment occurs due to the equilibrium between production, from several sources, and its removal by antioxidant enzymes and molecules. The instability of this balance can result in a pro-oxidant status, which has been defined as oxidative stress (1). Oxidative alterations have been concluded in carcinoma cells compared with healthy cells and this was regarded as an important factor for the disease. For the progression of breast cancer, risk factors might also contribute to ROS generation. Inherently, pro-oxidative conditions are associated with breast cancer. (2). By the progression of oxidative stress, cysteine residues and other thiol groups can undergo oxidation reaction by oxidant agents that present in the environment and this might lead to the formation of disulphide bridges and complex disulphide structures. On the other hand, disulphide bridges might be reduced to thiols, thus maintaining thiol/ disulphide equilibrium (3). The aspect of oxidative damage is associated with balance between oxidant and antioxidant systems. Endogenous antioxidant systems comprise antioxidant enzymes such as glutathione peroxidase, catalase, etc. (4). Myeloperoxidase (MPO) is an enzyme released during differentiation of myeloid cells. MPO is principally expressed in neutrophil cells. MPO plays an important role in various inflammatory pathways and is defined as an early marker for leucocyte infiltration or activity (5). Ischemia-modified albumin (IMA) was defined as a novel marker of ischemic damage. Serum IMA levels were widely determined for different types of ischemic diseases. It is a modified protein generated during acute ischemic conditions. IMA is a form of altered albumin which is produced during ischemia. Therefore, a variation in the binding capacity of albumin oc- curs for transition metals like cobalt, nickel, etc. During ischemia and reperfusion, this formation is also associated with oxidative stress (6). The relationship between breast cancer and oxidative stress, serum IMA levels might be considered as a reliable biomarker for chronic diseases. Prolidase is an exopeptidase that utilizes manganese as a cofactor and hydrolyzes $\mathrm{C}$-terminal peptite bonds of proline or hydroxyproline. Prolidase is involved in the final stage of collagen turnover, thus, it has a pivotal role in collagen metabolism, matrix remodeling, and cell maturation. Serum prolidase activity (SPA) has an important correlation with oxidative stress, therefore it might be accepted as a biomarker for oxidative stress. The levels of prolidase activity have been found to be elevated in various tumour tissues such as kidney and bladder (7). Our aim was to determine the levels of oxidative stress and antioxidant biomarkers such as IMA, MPO, prolidase, ceruloplasmin, catalase, serum native thiol, total thiol, disulphide levels, and disulphide/thiol equilibrium in subjects with breast cancer.

\section{Materials and Methods}

\section{Participants}

This study was conducted between March and June 2018, in Konya, Turkey. Eighty-two controls (aged between 32-67 years) and 127 breast cancer patients (aged between 27-66 years) [(Grade $1 \mathrm{n}=66$, Grade $2 \mathrm{n}=22$, Grade $3 \mathrm{n}=10$, and Grade 4 n=29)] admitted to Selcuk University Faculty of Medicine Hospital were enrolled. Patients were classified into thirteen different groups according to their medical theraphy such as: Group $1(\mathrm{n}=15)$ : Cyclophosphamide+doxorubicin+fluorouracil; Group $2(\mathrm{n}=11)$ : Trastuzumab+letrozole; Group 3 ( $\mathrm{n}=37)$ : Tamoxifen; Group $4(n=10)$ : Anastrozole; Group $5(n=12)$ : Only trastuzumab; Group $6(\mathrm{n}=17)$ : Paclitaxel; Group 7 (n=1): Trastuzumab+goserelin; Group 8 ( $\mathrm{n}=18)$ : Trastuzumab+paclitaxel; Group 9 
$(\mathrm{n}=1)$ : Cyclophosphamide+doxorubicin; Group $10(\mathrm{n}=1)$ : Fulvestrant; Group $11(\mathrm{n}=1)$ : Exemestane; Group $12(\mathrm{n}=1)$ : Cisplatin+etoposide; Group 13 (n=2): Capecitabine. Twenty-four of 127 patients $(\% 18.8)$ were operated on. The serum of these patients were collected before the operation. A written ethical approval form was obtained from all the participants and the study was approved by the local ethics committee. Participants with chronic diseases ( 5 with hypertension, 1 with coronary heart disease, 6 with diabetes, 1 with chronic kidney diseases, etc.), 16 with thyroid dysfunction and 59 with infections, inflammatory conditions, taking drugs and medications were excluded from this study. Inclusion criterion was to have informed consent.

\section{Collection of biological samples}

Ten milliliters of sample were collected in blood tubes (BD Vacutainer, USA) by venipuncture from each participant and analyzed within 3 days. The samples were centrifuged at $3500 \mathrm{rpm}$ for 10 minutes at $4{ }^{\circ} \mathrm{C}$, then the serum was separated and kept at $-80^{\circ} \mathrm{C}$ until analysis.

\section{Biochemical analysis}

Thiol- disulphides homeostasis parameters measurement. Thiol/Disulphide equilibrium assays were performed with automated spectrophotometric technique as described by Erel \& Neselioglu (8). Briefly, disulphide bridges were initially reduced to constitute free thiol groups by sodium borohydride. The remaining reductant agent sodium borohydride was depleted and removed by formaldehyde to impede reduction of DTNB (5,5'-dithiobis-(2-nitrobenzoic) acid), then all of the free thiol groups were measured after the reducing reaction. The active disulphide level is half of the difference between the total thiols and native thiols. Firstly native and total thiol amounts were measured, then disulphide levels, disulphide/total thiol percent ratios (SS/ $\mathrm{SH}+\mathrm{SS}$ ), disulphide/native thiol percent ratios
(SS/SH) and native thiol/total thiol percent ratios $(\mathrm{SH} / \mathrm{SH}+\mathrm{SS})$ were calculated by these results. These reagents were designed as a commercial kit (Relassay Diagnostic, Cat No:RL0185)

Catalase enzyme activity analysis. Catalase (CAT) enzyme activity was measured with a method modifed by Goth (9). Serum $(0.2 \mathrm{ml})$ was incubated in one milliliter substrate $(65$ $\mu$ mol per $\mathrm{H}_{2} \mathrm{O}_{2}$ (Sigma, Cat No:7722-84-1) in $60 \mathrm{mmol} / \mathrm{L}$ sodium-potassium phosphate buffer, $\mathrm{pH} 7.4$ ) at $37^{\circ} \mathrm{C}$ for 60 seconds. This enzyme catalyzed reaction was stopped with one milliliter of 32.4 millimolar ammonium molybdate (Sigma, Cat no:12054-85-2), and the yellow color of molybdate and hydrogen peroxide $\left(\mathrm{H}_{2} \mathrm{O}_{2}\right)$ was detected at $405 \mathrm{~nm}$ against a blank. One CAT unit decomposes $1 \mu \mathrm{mol}$ of $\mathrm{H}_{2} \mathrm{O}_{2} \mathrm{~min}^{-1}$ in this state. Results were expressed as $\mathrm{kU} / \mathrm{liter}$.

Measuring Myeloperoxidase activity. Human MPO activity was determined by a modified o-dianisidine dihydrochloride method (10) based on determination with kinetic method at $460 \mathrm{~nm}$ with intensity of the yellowish orange color of the product which is the formation from the oxidation of o-dianisidine dihydrochloride (Sigma, Cat No: 20325-40-0) with MPO in the existence of $\mathrm{H}_{2} \mathrm{O}_{2}$ (Sigma, Cat No:7722-84-1). One unit of MPO was described as that quenching $1 \mu \mathrm{mol}$ of $\mathrm{H}_{2} \mathrm{O}_{2}$ min- 1 at $25^{\circ} \mathrm{C}$. A molar extinction coefficient of $1.13 \times 10^{4}$ of oxidized o-dianisidine was used for the calculation. MPO activity was expressed as units per liter of serum.

Measurement of Ceruloplasmin. Ceruloplasmin (CLP) amounts were quantified by the method described by Erel O (11). This is an automated, colorimetric, enzymatic method and is based on the oxidation reaction of ferrous form to ferric ion. The measurement results were expressed in units per liter of serum. The precision of this assay is within $3 \%$. 
Prolidase Activity. Serum prolidase activity was analyzed according to the method described by Myara et al. $(12,13,14)$. Briefly, $100 \mu$ of serum physiological solution was added to $100 \mu$ of the serum samples. $25 \mu$ of the reaction mixture was incubated with $75 \mu \mathrm{l}$ of the preincubation mixture $(50 \mathrm{mmol} / 1$ Tris $\mathrm{HCl}$ buffer $\mathrm{pH} 7.0$ containing $1 \mathrm{mmol} / 1$ glutathione, $50 \mathrm{mmol} / 1 \mathrm{MnCl}_{2}$ ) at $37^{\circ} \mathrm{C}$ during 30 minutes. $100 \mu \mathrm{l}$ of $144 \mathrm{mmol} / 1$ gly-pro ( $\mathrm{pH} 7.8)$ solution was added to the reaction mixture then incubated at $37^{\circ} \mathrm{C}$ for $5 \mathrm{~min}-$ utes. To terminate the incubation reaction, $1 \mathrm{ml}$ glacial acetic acid was added. Then adding 300 $\mu \mathrm{l}$ Tris $\mathrm{HCl}$ buffer solution ( $\mathrm{pH}$ is adjusted 7.8) and $1 \mathrm{ml}$ ninhydrin reagent $(3 \mathrm{~g} / \mathrm{dl}$ ninhydrin was dissolved in $0.5 \mathrm{~mol} / 1$ orthophosphoric acid), the reaction mixture was incubated at $90^{\circ} \mathrm{C}$ for 20 minutes and cooled with ice. Absorbance was measured at a $515 \mathrm{~nm}$ wavelength to calculate proline levels.

Ischemia-modified Albumin Measurement. Albumin was analyzed with an Architect C16000 (Abbott Diagnostic,USA) system, utilizing the bromocresol green. IMA levels were measured with the method described by Bar O et al. (15). Briefly, $50 \mu$ of $0.1 \%$ cobalt chloride was added to $200 \mu \mathrm{l}$ of the serum samples then the reaction mixture was vortexed for 10 seconds and incubated for 10 minutes to provide the albumin-cobalt binding. Then, $50 \mu 1$ of Dithiothreitol (DTT) in a concentration of $1.5 \mathrm{mg} / \mathrm{mL}$ was added to the reaction mixture for a colorimetric reaction with cobalt, which was not bound to albumin and was incubated for 2 minutes. $1 \mathrm{~mL}$ of isotonic saline solution was added to the reaction mixture after incubation, and thus the reaction was stopped. The difference in the spectrofotometric measurements between the specimens and blank samples was expressed as serum IMA levels. These reagents were designed as a commercial kit (Relassay Diagnostic Cat No:RL0001)

\section{Statistical analysis}

For statistical analyses, SPSS version 18.0 statistical software was used. The accordance of continuous variables to normal distribution was analyzed with Shapiro - Wilk test. Statistical results of Gaussian distrubition of variables were expressed as mean \pm standard deviation. The existence of a statistically important difference between the groups in terms of continuous variables was assessed for parametric and nonparametric variables respectively with Student's t and Mann Whitney U tests. The correlation between the groups was examined with Spearman correlation test. $\mathrm{p}<0.05$ value was accepted statistically significant. Receiver operating characteristic (ROC) curves were designed via Medcalc v18.5.

\section{Results}

Demographic and laboratory data are presented in Table 1.

There were positive correlations between catalase and MPO $(\rho=0.352, p<0.001)$, catalase and DTTx100 $(\rho=0.527, p<0.001)$, catalase and prolidase $(\rho=0.369, p<0.001)$, ceruloplasmin and MPO $(\rho=0.605, p<0.001)$, MPO and prolidase $(\rho=0.220, p=0.001)$, MPO and DTTx100 $(\rho=0.239, \quad p<0.001)$, prolidase and DTTx100 $(\rho=0.353, p<0.001)$.

According to grade classification, only NT was found to be statistically different between groups (Table 2).

According to ROC curves, area under curve (AUC) values were $0.82(0.76-0.87 ; \% 95 \mathrm{CI})$, 0.57 (0.49-0.63; \%95 CI), 0.75 (0.69-0.81; \%95 CI), 0.88 (0.84-0.94; \%95 CI), 0.83 (0.77-0.88; $\% 95 \mathrm{CI}$ ) and 0.83 (0.77-0.88; \%95 CI) for serum catalase, IMA, MPO, prolidase, DTTx100 and NTTx100, respectively (Figure 1). Serum prolidase activity expressed the optimal AUC of 0.88 (0.84-0.94; \%95 CI) for $1820 \mathrm{U} / \mathrm{L}$ cut-off value (Figure 1 and 2) 
Table 1. Demographic and laboratory parameters of both groups.

\begin{tabular}{lccc}
\hline & Control $(\mathbf{n}=\mathbf{8 2})$ & Patients $(\mathbf{n}=\mathbf{1 2 7})$ & $\mathbf{p}$ \\
\hline Catalase $(\mathrm{kU} / \mathrm{L})$ & $81.6(18.2-322.9)$ & $199.3(16.4-489.9)$ & $<0.001$ \\
\hline Ceruloplasmin $(\mathrm{U} / \mathrm{L})$ & $670 \pm 135$ & $675 \pm 124$ & 0.760 \\
\hline MPO $(\mathrm{U} / \mathrm{L})$ & $101 \pm 31$ & $124 \pm 28$ & $<0.001$ \\
\hline NT $(\mu \mathrm{mol} / \mathrm{L})$ & $391 \pm 52$ & $342 \pm 60$ & $<0.001$ \\
\hline TT $(\mu \mathrm{mol} / \mathrm{L})$ & $430 \pm 52$ & $396 \pm 56$ & $<0.001$ \\
\hline NTTx100 & $91(73-99)$ & $87(58-93)$ & $<0.001$ \\
\hline DS $(\mu \mathrm{mol} / \mathrm{L})$ & $18(2-41)$ & $25(11-61)$ & $<0.001$ \\
\hline DNTx100 & $4.7(0.5-17.7)$ & $7.1(3.4-34.0)$ & $<0.001$ \\
\hline DTTx100 & $4.3(0.5-13.1)$ & $6.2(3.2-20.5)$ & $<0.001$ \\
\hline IMA $($ ABSU) & $0.62(0.19-1.31)$ & $0.66(0.31-3.30)$ & 0.031 \\
\hline Prolidase $(\mathrm{U} / \mathrm{L})$ & $1456 \pm 401$ & $2217 \pm 538$ & $<0.001$ \\
\hline Age & $52(32-67)$ & $52(27-66)$ & 0.058 \\
\hline
\end{tabular}

$\mathrm{NT}=$ native thiol, TT=total thiol, NTT=native thiol/total thiol, DS=disulphide, DNT= disulphide/native thiol, DTT= disulphide/ total thiol, $\mathrm{ABSU}=\mathrm{Absorbance}$ unit, $\mathrm{MPO}=$ myeloperoxidase, $\mathrm{IMA}=$ ischemia-modified albumin.

Table 2. Demographic and laboratory parameters of breast cancer patients.

\begin{tabular}{|c|c|c|c|c|c|}
\hline & Grade $1(n=66)$ & Grade $2(n=22)$ & Grade $3(n=10)$ & Grade $4(n=29)$ & $\mathbf{p}$ \\
\hline Catalase $(\mathrm{kU} / \mathrm{L})$ & $180.4(27.2-413.7)$ & $239.2(76.2-489.9)$ & $175.2(16.4-465.0)$ & $202.9(32.5-360.5)$ & 0.089 \\
\hline $\begin{array}{l}\text { Ceruloplasmin } \\
\text { (U/L) }\end{array}$ & $677 \pm 122$ & $664 \pm 104$ & $675 \pm 143$ & $691 \pm 141$ & 0.919 \\
\hline MPO (U/L) & $126 \pm 25$ & $122 \pm 31$ & $116 \pm 31$ & $125 \pm 30$ & 0.764 \\
\hline $\mathrm{NT}(\mu \mathrm{mol} / \mathrm{L})$ & $351 \pm 58$ & $311 \pm 54$ & $360 \pm 74$ & $335 \pm 58$ & 0.035 \\
\hline $\mathrm{TT}(\mu \mathrm{mol} / \mathrm{L})$ & $404 \pm 57$ & $372 \pm 38$ & $409 \pm 70$ & $389 \pm 55$ & 0.091 \\
\hline NTTx100 & $87(71-93)$ & $85(58-90)$ & $89(68-92)$ & $87(68-92)$ & 0.062 \\
\hline $\mathrm{DS}(\mu \mathrm{mol} / \mathrm{L})$ & $25(11-49)$ & $27(18-61)$ & $23(14-44)$ & $23(13-57)$ & 0.161 \\
\hline DNTx100 & $7.1(3.4-19.8)$ & $8.3(5.2-34.0)$ & $6.0(3.9-22.8)$ & $7.2(4.0-23.5)$ & 0.062 \\
\hline DTTx100 & $6.2(3.2-14.1)$ & $7.1(4.7-20.5)$ & $5.3(3.6-15.6)$ & $6.3(3.7-16.0)$ & 0.062 \\
\hline IMA (ABSU) & $0.67(0.31-3.30)$ & $0.60(0.46-2.96)$ & $0.57(0.41-0.85)$ & $0.71(0.38-2.43)$ & 0.111 \\
\hline Prolidase (U/L) & $2274 \pm 592$ & $2253 \pm 590$ & $2029 \pm 271$ & $2082 \pm 407$ & 0.284 \\
\hline Age & $52(28-66)$ & $56(27-62)$ & $50(39-60)$ & $53(29-66)$ & 0.519 \\
\hline
\end{tabular}

$\mathrm{NT}=$ native thiol, $\mathrm{TT}=$ total thiol, $\mathrm{NTT}=$ native thiol/total thiol, $\mathrm{DS}=$ disulphide, $\mathrm{DNT}=$ disulphide/native thiol, $\mathrm{DTT}=$ disulphide/ total thiol, $\mathrm{ABSU}=\mathrm{Absorbance}$ unit, $\mathrm{MPO}=$ myeloperoxidase, $\mathrm{IMA}=$ ischemia-modified albumin. 


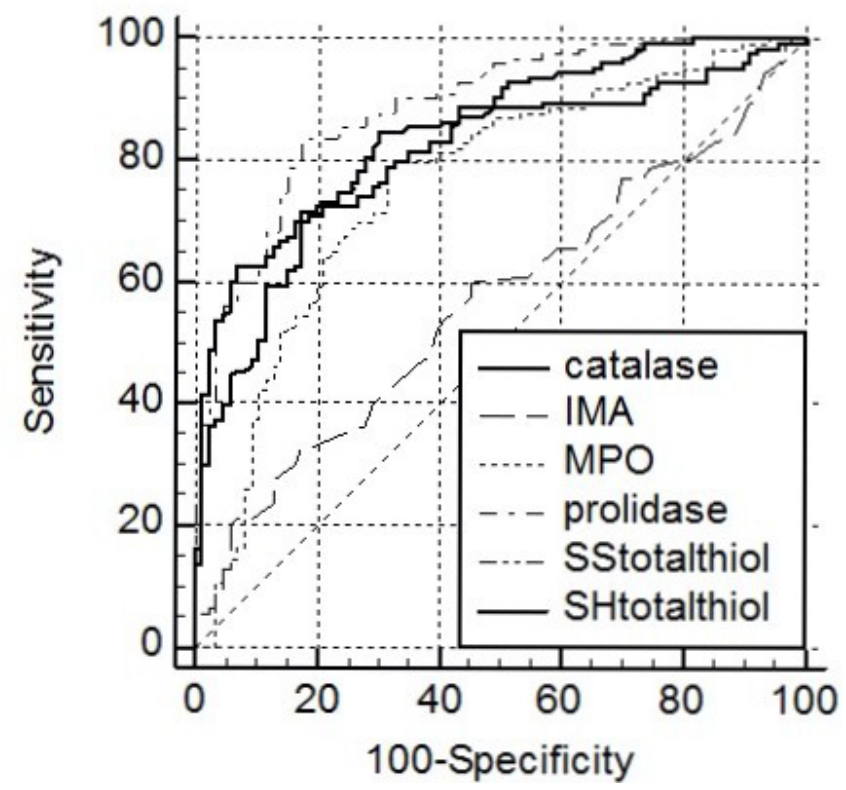

Fig. 1. Comparison of ROC curves for serum catalase, IMA, MPO, prolidase, SS total thiol (DTTx100) and SH total thiol (NTTx100). IMA=ischemia-modified albumin, MPO=myeloperoxidase, DTT= disulphide/total thiol, $\mathrm{SS}=$ disulphide, $\mathrm{SH}=$ native thiol

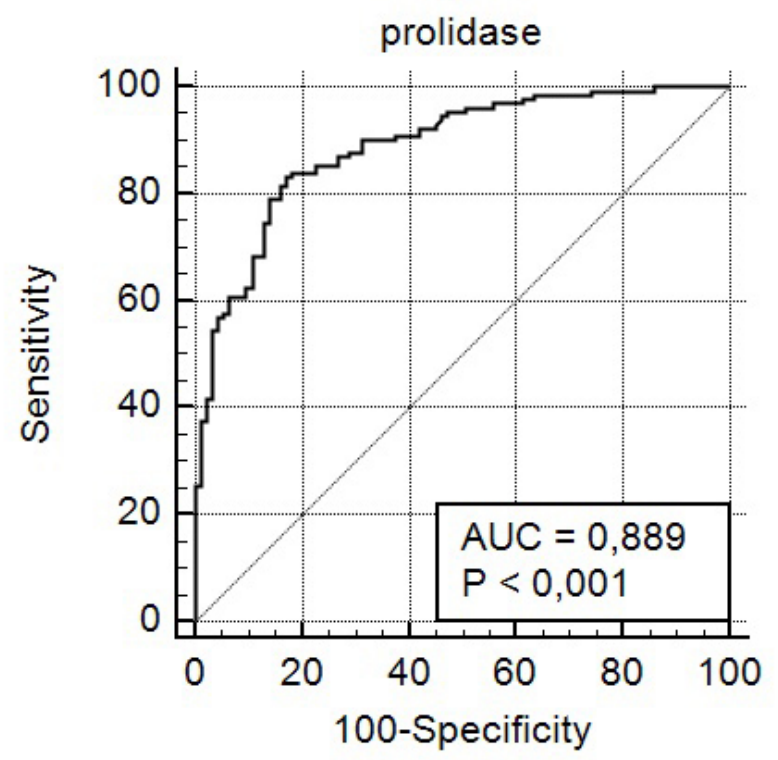

Fig. 2. ROC curve of serum prolidase. ROC: Receiver operating characteristic

\section{Discussions}

The assessment of the redox conditions of patients with breast cancer demonstrates a new way to study the role of redox systems and pro-oxidant/antioxidant factors related to the progression of this disease. There are antiodixant mechanisms that protect the cells againts 
reactive oxygene species such as catalase. Also, there are contradictory results regarding antioxidant defence biomarkers such as catalase. Although studies demonstrate no statistical change (16), decreased acitivity of catalase in patients with breast cancer (17), some studies reported that catalase activity was elevated. Ramírez-Expósito et al. reported that serum superoxide dismutase and catalase activity was elevated in metastases of breast cancer (18). In this study, elevated catalase activity in patients with breast cancer might be due to the implementation of antioxidant systems as a reflex defense mechanism against oxidative stress. Also, as consistent with the results of this study, Coelho et al. (19) reported that serum MPO levels of patients with breast cancer were higher than in the control group ( $p$ $=0.002$ ). This elevation might reflect the oxidative course of the disease. Increased production of reactive oxygen species (ROS) overwhelms the antioxidant defense system and, thus, cells are exposed to oxidative stress. It arises from the lack of antioxidant defense as well as elevated free radical levels. The thiol groups of sulfur containing amino acids (cysteine and methionine, etc.) in proteins are oxidized by oxygen radicals and converted to reversible disulphide bridges. The conformational and functional changes in physiological proteins occur due to the loss of -SH groups. -SH groups attempting to impede the harmful effects of free radicals might decrease the serum and tissue concentrations of these radicals (20). Thiol/disulphide status was determined in diseases such as Familial Mediterranean fever (21), fibromyalgia (22), coronary artery disease (23), non-small cell lung cancer (24). In this study it was found that native thiol (NT) $[342 \pm 60 \mathrm{vs} 391 \pm 52 \mu \mathrm{mol} / \mathrm{L}]$ and total thiol levels (TT) $[396 \pm 56$ vs $430 \pm 52 \mu \mathrm{mol} / \mathrm{L}]$ were lower in patients' serum than the control group (For both $\mathrm{p}<0.001$ ). In contrast to this finding, serum disulphide concentrations of patients were significantly higher compared with the control group [25 (11-61) vs 18 (2-41) $\mu \mathrm{mol} / \mathrm{L}]$ (Table I). These results demonstrated higher oxidative status of breast cancer patients.

When the healthy tissue was in oxidative stress, levels of hydroxyl radicals increased. Albumin was modified by the hydroxyl radical leading to the formation of IMA. It was pointed out for the first time that the formation of IMA is directly related to this production of active oxidation species and confirmed that hydroxyl radicals play an important role in the formation of IMA (25). It was concluded that serum IMA amounts were elevated in patients with breast cancer (26). Also in our study, serum IMA concentrations were found to be statistically higher than in the control group ( $\mathrm{p}=0.031)$ (Table I).

In order to find out the diagnostic efficiency of oxidative status for biomarkers in patients with breast cancer, ROC curve analysis was performed and it was found that serum prolidase activity presented optimal AUC of 0.88 for 1820 U/L cut-off value (Figure 2 ).

Oxidative damage parameters might serve as important guides for diagnosis and treatment of breast cancer. The combination of thiol-disulphide status and other oxidative stress biomarkers such as prolidase, ischemia-modified albumin could be more useful for clinical examination of patients with breast cancer. These oxidative stress parameters might be reliable markers for the course of breast cancer.

\section{Authors' contribution}

SA: Conceptualization; Data curation; Validation

DE: Data curation; Methodology; Writing original draft

CB: Conceptualization; Methodology

$\mathrm{CN}$ : Formal analysis; Visualization

EO: Conceptualization; Supervision 
MY: Investigation; Methodology

SC: Conceptualization

AU: Conceptualization; Writing - review \& editing

\section{Acknowledgments}

No funding from any establishment was accepted for our project, and the authors' time on this project was supported by their employers.

\section{Conflict of interest}

The authors declare no conflict of interest.

\section{List of Abbreviations}

ABSU: Absorbance Unit, ROS: Reactive Oxygen Species, MPO: Myeloperoxidase, IMA: Ischemia-modified albümin, SPA: Serum prolidase activity, BD: Becton Dickinson, USA: United States of America, DTNB: 5,5'-dithiobis-(2-nitrobenzoic) acid, SS: disulphide, $\mathrm{SH}$ : native thiol, CAT: Catalase, $\mathrm{H}_{2} \mathrm{O}_{2}$ :Hydrogen peroxide, CLP: Ceruloplasmin, $\mathrm{HCl}$ : Hydrochloric acid, DTT: Dithiothreitol, CV: Coefficent of variation, ROC: Receiver operating characteristic, $\mathrm{NT}=$ native thiol, $\mathrm{TT}=$ total thiol, $\mathrm{NTT}=$ native thiol/total thiol, $\mathrm{DS}=$ disulphide, $\mathrm{DNT}=$ disulphide/native thiol, DTT=disulphide/total thiol, AUC: Area under curve

\section{References}

1. Hecht F, Pessoa CF, Gentile LB, Rosenthal D, Carvalho DP, Fortunato RS. The role of oxidative stress on breast cancer development and therapy. Tumour Biol. 2016 Apr; 37(4):4281-91. DOI: 10.1007/s13277-016-4873-9

2. Mencalha A, Victorino VJ, Cecchini R, Panis C. Mapping oxidative changes in breast cancer:understanding the basic to reach the clinics. Anticancer Res. 2014 Mar; 34(3):1127-40.

3. Guney T, Kanat IF, Alkan A, Alisik M, Akinci S, Silay K, et al. Assessment of serum thiol/disulfide homeostasis in multiple myeloma patients by a new method. Redox Rep. 2017 Nov; 22(6):246-51. DOI:
10.1080/13510002.2016.1180100

4. Elmas B, Erel O, Ersavaş D, Yurumez Y. Thiol/disulfide homeostasis as a novel indicator of oxidative stress in children with simple febrile seizures. Neurol Sci. 2017 Nov; 38(11):1969-75. DOI: 10.1007/s10072-0173087-2

5. Coelho BA, Belo AV, Andrade SP, Amorim WC, Uemura G, da Silva Filho AL. N-acetylglucosaminidase, myeloperoxidase and vascular endothelial growth factor serum levels in breast cancer patients. Biomed Pharmacother. 2014 Mar; 68(2):185-9. DOI: 10.1016/j. biopha.2013.10.009

6. Jena I, Nayak SR, Behera S, Singh B, Ray S, Jena D, et al. Evaluation of ischemia-modified albumin, oxidative stress, and antioxidant status in acute ischemic stroke patients. J Nat Sci Biol Med. 2017 Jan-Jun; 8(1):110113. DOI: 10.4103/0976-9668.198346

7. Kucukdurmaz F, Efe E, Celik A, Dagli H, Kılınc M, Resim S. Evaluation of serum prolidase activity and oxidative stress markers in men with $\mathrm{BPH}$ and prostate cancer. BMC Urol. 2017 Dec; 17(1):116. DOI: 10.1186/s12894-017-0303-6

8. Erel O. Neselioglu S. A novel and automated assay for thiol/disulfide homeostasis. Clin Biochem. 2014 Dec; 47(18):326-32. DOI: 10.1016/j.clinbiochem.2014.09.026

9. Goth L. A simple method for determination of serum catalase activity and revision of reference range. Clin Chim Acta. 1991 Feb; 196(2-3):143-152. DOI: 10.1016/0009-8981(91)90067-M

10. Bradley PP, Priebat DA, Christensen RD, Rothstein G. Measurement of cutaneous inflammation:estimation of neutrophil content with an enzyme marker. J Invest Dermatol. 1982 Mar; 78(3):206-9. DOI: 10.1111/15231747.ep12506462

11. Erel O. Automated measurement of serum ferroxidase activity. Clin Chem. 1998 Nov; 44(11):313-9.

12. Myara I, Myara A, Mangeot M, Fabre M, Charpentier C, Lemonnier A. Plasma prolidase activity:a possible index of collagen catabolism in chronic liver disease. Clin Chem. 1984 Feb; 30(2):211-5.

13. Myara I, Charpentier C, Lemonnier A. Optimal conditions for prolidase assay by proline colorimetric determination:application to iminodipeptiduria. Clin Chim Acta. 1982 Oct; 125(2):193-205. DOI: 10.1016/00098981(82)90196-6

14. Chinard FP. Photometric estimation of proline and orni- 
thine. J Biol Chem. 1952 Nov; 199(1):91-95.

15. Bar-Or D, Lau E, Winkler JV. A novel assay for cobalt-albumin binding and its potential as a marker for myocardial ischemia-a preliminary report. J Emerg Med. 2000 Nov; 19(4):311-5. DOI: 10.1016/S07364679(00)00255-9

16. Badid N, Ahmed FZ, Merzouk H, Belbraouet S, Mokhtari N, Merzouk SA, et al. . Oxidant/antioxidant status, lipids and hormonal profile in overweight women with breast cancer. Pathol Oncol Res. 2010 Jun; 16(2):159-67. DOI: 10.1007/s12253-009-9199-0

17. Punnonen K, Ahotupa M, Asaishi K, Hyöty M, Kudo R, Punnonen R. Antioxidant enzyme activities and oxidative stress in human breast cancer. J Cancer Res Clin Oncol. 1994 Jun; 120(6):374-7. DOI: 10.1007/ BF01247464

18. Ramírez-Expósito MJ, Urbano-Polo N, Due-as B, Navarro-Cecilia J, Ramírez-Tortosa C, Martín-Salvago $\mathrm{MD}$, et al. Redox status in the sentinel lymph node of women with breast cancer. Ups J Med Sci. 2017 Dec; 122(4):207-16. DOI: 10.1080/03009734.2017.1403522

19. Coelho BA, Belo AV, Andrade SP, Amorim WC, Uemura G, da Silva Filho AL. N- acetylglucosaminidase, myeloperoxidase and vascular endothelial growth factor serum levelsin breast cancer patients. Biomed Pharmacother. 2014 Mar; 68(2):185-9. DOI: 10.1016/j.biopha.2013.10.009

20. Topuz M, Şen O, Kaplan M, Akkus O, Erel O, Gur M. The Role of Thiol/Disulphide Homeostasis in Anthracycline Associated Cardiac Toxicity. Int Heart J. 2017
Feb; 58(1):69-72. DOI: 10.1536/ihj.16-124

21. Omma A, Sandikci SC, Kücüksahin O, Alisik M, Erel O. Can the Thiol / Disulfide Imbalance Be a Predictor of Colchicine Resistance in Familial Mediterranean Fever? J Korean Med Sci. 2017 Oct; 32(10):1588-94. DOI: $10.3346 / \mathrm{jkms} .2017 .32 .10 .1588$

22. Fidan F, Alkan BM, Ugurlu FG, Bozkurt S, Sezer N, Bicer C, et al. Dynamic Thiol/Disulphide Homeostasis in Patients With Fibromyalgia. Arch Rheumatol. 2017 Jul; 32(2):112-7. DOI: 10.5606/ArchRheumatol.2017.5931

23. Altıparmak IH, Erkuş ME, Sezen H, Demirbag R, Gunebakmaz O, Kaya Z, et al. The relation of serum thiol levels and thiol/disulphide homeostasis with the severity of coronary artery disease. Kardiol Pol. 2016 May; 74(11):1346-53. DOI: 10.5603/KP.a2016.0085

24. Dirican N, Dirican A, Sen O, Aynali A, Atalay S, Bircan HA, et al. Thiol/disulfide homeostasis:A prognostic biomarker for patients with advanced non-small celllung cancer? Redox Rep. 2016 Sep; 21(5):197-203. DOI: $10.1179 / 1351000215 Y .0000000027$

25. Luan XD, Zhao KH, Hou H, Gai YH, Wang QT, Mu Q, et al. Changes in ischemia modified albumin in myocardial toxicity induced by anthracycline and docetaxel chemotherapy. Medicine (Baltimore). 2017 Aug; 96(32):e7681. DOI: 10.1097/MD.0000000000007681

26. Ma Y, Kang W, Bao Y, Jiao F, Ma Y. Clinical significance of ischemia-modified albumin in the diagnosis of doxorubicin-inducedmyocardial injury in breast cancer patients. PLoS One. 2013 Nov; 8(11):e79426. DOI: 10.1371/journal.pone.0079426 